\title{
Knowledge, Attitude and Practice about Hearing Impairment among the parents of children posted for Cochlear Implantation
}

Upadhyay Riddhima,

Rajesh Ranjan*

\begin{abstract}
Introduction: Audition is essential for communication, and it is vital for the normal cognitive development of children. Hence, if a child has a hearing impairment, it would significantly impact the child's speech and language development, competence, and emotional wellness. Most children with hearing impairment are advised to go for amplification devices or cochlear implantations for communication through oral modality. There are numerous factors upon which the rehabilitation programs' outcomes depend; one critical aspect that influences habilitation/rehabilitation is parents' knowledge regarding hearing impairment, their attitude towards it, and their practice. Therefore, it needed to assess the parental knowledge, attitude, and practice among parents of children with hearing impairment.
\end{abstract}

Method: The study used a cross-sectional study design and a convenient sampling method to recruit the participants. It was a timebound study; all the cases were recruited as participants during the study period.

Results: The developed questionnaire has good reliability and validity. The questionnaire was administered to 38 parents to assess their knowledge, attitude, and practice towards their children's hearing impairment. The study's finding revealed that the overall parental knowledge, attitude, and practice towards their children's hearing impairment was found to be good.

Conclusion: The developed questionnaires in Hindi have good reliability and validity to assess parental knowledge, attitude, and practice about hearing impairment among parents of children with hearing impairment.

Keywords: Hearing impairment, Cochlear implant, Parents, Knowledge, Attitude, Practice

Department of Audiology and Speech Language Pathology, Kasturba Medical College , Mangalore, Manipal Academy of Higher Education, Manipal, Karnataka, India. E-mail: rajesh.ranjan@manipal.edu Phone: +91-9480138057

Paper submitted on July 27, 2021; and Accepted on December 23, 2021 


\section{INTRODUCTION}

Audition is essential for communication, and it is vital for the normal cognitive development of children. Audition heavily influences communication. Hence, if a child has a hearing impairment $(\mathrm{HI})$, it would significantly impact the child's speech and language development, competence, and emotional wellness. Most children with $(\mathrm{HI})$ are advised to go for amplification devices or cochlear implantations $(\mathrm{Cl})$ for communication through oral modality. To maximize the benefits of the hard-of-hearing child, parents play an essential role in the habilitation/ rehabilitation process ${ }^{1}$. There are numerous factors upon which the hablitation/rehabilitation programs' outcomes depend, including the onset of hearing loss, age of the diagnosis, age of intervention, family involvement, poor economic, education, and social background ${ }^{2}$. One more critical aspect that influences habilitation/rehabilitation is parents' knowledge regarding $\mathrm{HI}$, their attitude towards it, and their practice. There is significant variability among the parents' reactions towards the diagnosis of hearing loss in their children. The varied reactions are influenced by several factors, including their knowledge about $\mathrm{HI}$ and social or cultural beliefs. Some parents might have misconceptions or unjustified concerns. Parental knowledge towards $\mathrm{HI}$ and hearing services can change their attitude towards child's $\mathrm{HI}^{3,4}$. Fewer studies reported on parental knowledge, attitude, and practice for the best outcome from habitation/ rehabilitation. Therefore, study was planned to understand parental knowledge, attitude, and practice among parents of children with $\mathrm{HI}$ planned to receive $\mathrm{Cl}$.

\section{METHODS}

The present study used a cross-sectional study design and a convenient sampling method to recruit the participants. As it was a time-bound study, all the cases were recruited as participants during the study period.

\section{Participants}

A total of 38 parents participated in this study, both the parents together filled the questionnaire. The participants were parents of children with severe to profound $\mathrm{HI}$ planned for $\mathrm{Cl}$ under government schemes were included in the study. Parents with $\mathrm{HI}$ and parents of children with $\mathrm{HI}$ planned for $\mathrm{Cl}$ with associated co-morbid disabilities were excluded.

\section{Age of the Parents}

The youngest participants among both fathers and mothers were of 23 years and the oldest participants among fathers were 44 years, and among mothers was 33 years old. The majority of the participants among fathers who filled the questionnaire were in the 26-35 years age group with 31 fathers, followed by 6 fathers were in the age group of 36-45 years, and 1 father were in the age group of $<25$ years old. In contrast, among mothers, 22 mothers were in the age group of 26-35 years range, followed by 2 mothers were in the age group of 36-
45 years old and remaining 14 mothers were in the age group of $<25$ years.

\section{Parents Education Level and Profession}

Out of 38 parents, the majority of the parents had secondary level of education, with 24 fathers and 17 mothers and primary education was obtained by 6 fathers, and 8 mothers. Among the remaining parents, 4 fathers and 7 mothers were illiterate, and only 4 fathers and 6 mothers were having a college degree. The majority of the parents earning source was through unskilled profession with 22 fathers and 13 mothers, followed by 16 fathers and 3 mothers earning through skilled profession and among mothers 22 were housewives.

\section{Procedure}

The study was conducted in 3 phases

\section{Phase I}

A questionnaire was developed in Hindi to assess knowledge, attitude, and practice among parents of children who were to receive $\mathrm{Cl}$ surgery based upon a literature review and opinion from experts having experience in the $\mathrm{Cl}$ recipient team. The questionnaire consisted of both open as well as closed-ended questions. This is because open-ended questions allow deeper reflection of their response and stimulate respondents to think and express their feelings. Closedended questions were also used due to the time required and the respondent's immediate response to the study's questions ${ }^{5}$. The questionnaire consisted of 45 questions and was divided into the knowledge section, which had 16 questions, the attitude section had 17 sets of questions, and the practice section consisted of 12 questions. It also consisted of the socio-demographic section to collect information about parents name, age, occupation, education level, language preferred by them, contact number, and the name of the child, age, gender, at which age the problem was noticed first, in which ear the child had hearing loss, type and degree of the hearing loss, way of communication, and any family history related to HI.

The Rating System of the Questionnaire: Each section in the questionnaire was designed with a different rating system.

Knowledge section consisted of "yes" or "no" options translated to Hindi. The 'yes' option depicts the correct answer, and the 'no' option describes the wrong answer. Those parents who chose 'yes' options had high knowledge levels compared to those who chose the 'no' option. Attitude section consisted of a descriptive rating scale where "always," "often," "sometimes," "seldom," "never" were the options that were used to assess the parent's attitude, feeling, and belief regarding their children's HI. The ratings were translated to Hindi. Practice section consisted of both open as well as closeended questions. The mode of response in the practice section consisted of "yes" or "no" options. Two questions 
used a different rating scale in which one used "very satisfied," "satisfied," "neither satisfied nor dissatisfied," "dissatisfied" and "very dissatisfied," options and another question used with "not at all, "partially," "fully" options. The ratings were translated to Hindi.

\section{Phase II}

Content validation was done in the second phase of the study. The questionnaire was sent via mail to the five audiologists with a master's degree having more than five years of experience in $\mathrm{Cl}$ for the validation procedure. The experts were asked to validate the questionnaire based on the questions' relevance in all three sections. They were also asked to provide feedback regarding the questions classified under suitable categories, i.e., Knowledge, Attitude, and Practice. They were asked to assess if the questionnaire's language is easily understandable for the patient's parents. The 5-point rating scale was attached along with the questionnaire to perform the content validation. The suggestions provided were taken after getting responses from the audiologists, and the content validation index was calculated to finalize the questions. Table 1 depicts the fivepoint rating scale to rate the questions' relevance in the questionnaire used by experts.

The calculation of the CVI included two steps. The first step, the content validity Index for items (I-CVI), was estimated. The experts rated all the questions using the desired rating scale to know the items' relevance in the developed questionnaire. Questions that had relevant ratings were taken in the final version of the questionnaire. In the second step, the content validity index for Sales (S-CVI) was calculated using two ways. First, the proportions of all the items that acquired the relevant ratings by all the experts were taken, and second is by taking an average of $\mathrm{I}-\mathrm{CVI}$ for all the questionnaire questions ${ }^{6}$.

CVI was calculated using the following equation as follows:-

CVI: Number of the desired rating obtained by the Experts Total Number of Experts.
All the questions that had a relevant rating of " 4 " or " 5 " to obtain a criterion point higher than or equal to 0.8 , which was stated as the criteria point by Polit and Beck, (2004) for CVI, were included, and questions that have had CVI rating below 0.8 were discarded.

\section{Phase III}

Data collection and statistical analysis were performed. The hard copy of the validated questionnaire was provided to the parents after obtaining consent from them. Parents were given instructions on how to fill the questionnaire. The analysis was done using Statistical Package for the Social Sciences (SPSS) software version 25.0. The data were described using descriptive statistics such as frequency and percentage of parent's response under all three sections. The significance of socio-demographic variables (parental age, education level, and profession) and parental knowledge, attitude, and practice towards their children's HI was examined.

To examine the association between socio-demographic variables and parental knowledge, attitude, and practice towards their children's $\mathrm{HI}$, the points were assigned under the knowledge section to the response options; 1 point for a correct answer and 2 points for a wrong answer was given. So, the final score range, i.e., 1 to 28 points, was further classified as 'good knowledge,' for scores ranging between 14- 19, 'fair knowledge' for scores ranging between 20-25, and 'bad knowledge' for scores $>26$. The practice scores range, i.e., 1 to 12 points and was further classified as 'good practice,' for scores ranging from 6-8, 'fair practice' for scores ranging between 9-10, and 'bad practice' for scores ranging between 11-12. The attitude section consisted of negative questions. The scoring was assigned 1 point for 'always,' 2 points for 'often,' 3 points for 'sometimes,' 4 points for 'seldom,' and 5 points for 'never' options. So, the final score range, i.e., 1 to 60 points, was further classified as 'good attitude,' for scores $>45$ scores, 'fair attitude' for scores ranging between 28-44, and 'poor attitude' for scores ranging between 12-28. Table 2 shows the statistical tests used during the analysis.

Table 1. Five-point rating scale to rate the relevance of the questions in the questionnaire by the experts.

\begin{tabular}{cc}
\hline Scale & Interpretation \\
\hline 5 & very strongly valid \\
4 & high valid \\
3 & valid \\
2 & Less valid \\
1 & not valid \\
\hline
\end{tabular}

Table 2. Specific statistical tests used in the study.

\section{Statistical Aim}

To assess the content validity of the questionnaire.

To assess the internal consistency of the questionnaire.

To assess the reliability of the questionnaire.

\section{Statistical Tests Used}

Content validation Index (7). Guttman Split Half Coefficient.

Guttman Split Half Coefficient. 


\section{RESULTS}

\section{Validation of the Questionnaire}

The tables 3, 4, and 5 depict the content validity index for each question under knowledge, attitude, and practice section.

After the validation procedure, the final version of the questionnaire consisted of 38 questions. Questions under knowledge were 14; the attitude section has 12 sets of questions, and the practice section consisted of 12 questions.

\section{Reliability of the Questionnaire}

The questionnaire was administered to ten parents to check the internal consistency. The internal consistency of the questionnaire's content was assessed using split-half test of reliability to calculate the Guttman splithalf Coefficient. Mohamad et al. $(2015)^{8}$ stated that a correlation coefficient of 0.70 and above is enough to show test items to be reliable. The Guttman split-half Coefficient values for all three sections are given in Table 6.

The analysis revealed that the questionnaire was highly reliable, and under all three sections, the reliability ranged from 0.94 to 1 .

\section{Parental Knowledge on Hearing Impairment}

The "K1", "K2", and "K3" represented the number of the question under the knowledge section and the percentage of correct/incorrect responses described in the yes/no section. Table 7 depicts the parents' knowledge about their children's hearing impairment.

\section{Parental Attitude towards Hearing Impairment}

The "A1", "A2", "A3" represented the number of the question under the attitude section. Table 8 depicts the parents' attitude towards their children's hearing impairment.

\section{Parental Practice towards Hearing Impairment}

Table 9 depicts the parents' practice towards their children's hearing impairment. The "P1", "P3", P4" represented the practice question number.

Question 2 was open-ended, 'from where did you come to know that audiologists investigate hearing-related problems.' depicts a source from where parents came to learn about the Audiologists profession

For question 5, 'has your child ever used hearing aids, and has it showed any improvement,' 18 (47.4\%) parents reported 'never used it,' followed by 15 (39.5\%) parents who reported 'used it but not useful.' The remaining $4(10.5 \%)$ parents reported 'used it, little useful' and 1 (2.6\%) parent responded, 'is very useful'.

Question 8 was open-ended, 'what do you expect from a $\mathrm{Cl}$ after you enrolled your child's name for surgery?' All the parents responded that they expect their child to hear and speak like typically developed children.

For question 9, 'do you think a $\mathrm{Cl}$ will become a part of your child's life, out of 38 parents, 33 (86.8\%) parents responded 'completely' would become a part of their children's life. In contrast, few 4 (10.5\%) parents responded 'partially' and 1 (2.6\%) parent responded, 'not at all.'

Association between Parental Knowledge, Attitude, and Practice with Parents Age, Education level, and Profession towards their children with Hearing Impairment

Table 10 depicts the association between parental knowledge, attitude, and practice with parents age, education level, and profession towards their children with hearing impairment.

Table 3. CVI for each question obtained from all the five experts under the 'Knowledge' section.

\begin{tabular}{|c|c|c|c|}
\hline \multicolumn{4}{|c|}{ Knowledge Section } \\
\hline Questions & No. in Agreement & Total number of Experts & CVI \\
\hline $\mathrm{K} 1$ & 5 & 5 & $1^{*}$ \\
\hline K2 & 3 & 5 & 0.6 \\
\hline K3 & 3 & 5 & 0.6 \\
\hline K4 & 5 & 5 & $1^{*}$ \\
\hline K5 & 5 & 5 & $1^{*}$ \\
\hline K6 & 4 & 5 & $0.8^{*}$ \\
\hline K7 & 5 & 5 & $1^{*}$ \\
\hline K8 & 4 & 5 & $0.8^{*}$ \\
\hline K9 & 4 & 5 & $0.8^{*}$ \\
\hline $\mathrm{K} 10$ & 5 & 5 & $1^{*}$ \\
\hline $\mathrm{K} 11$ & 5 & 5 & $1^{*}$ \\
\hline $\mathrm{K} 12$ & 4 & 5 & $0.8^{*}$ \\
\hline $\mathrm{K} 13$ & 5 & 5 & $1^{*}$ \\
\hline $\mathrm{K} 14$ & 5 & 5 & $1^{*}$ \\
\hline K15 & 5 & 5 & $1^{*}$ \\
\hline K16 & 5 & 5 & $1^{*}$ \\
\hline
\end{tabular}


Table 4. CVI for each question obtained from all the five experts under the 'Attitude' section.

\begin{tabular}{|c|c|c|c|}
\hline \multicolumn{4}{|c|}{ Attitude Section } \\
\hline Questions & No. in Agreement & Total number of Experts & CVI \\
\hline $\mathrm{A} 1$ & 5 & 5 & $1^{*}$ \\
\hline $\mathrm{A} 2$ & 4 & 5 & $0.8^{*}$ \\
\hline A3 & 3 & 5 & 0.6 \\
\hline $\mathrm{A} 4$ & 4 & 5 & $0.8^{*}$ \\
\hline A5 & 3 & 5 & 0.6 \\
\hline A6 & 3 & 5 & 0.6 \\
\hline A7 & 5 & 5 & $1^{*}$ \\
\hline A8 & 5 & 5 & $1^{*}$ \\
\hline A9 & 5 & 5 & $1^{*}$ \\
\hline A10 & 4 & 5 & $0.8^{*}$ \\
\hline $\mathrm{A} 11$ & 2 & 5 & 0.4 \\
\hline $\mathrm{A} 12$ & 2 & 5 & 0.4 \\
\hline $\mathrm{A} 13$ & 5 & 5 & $1 *$ \\
\hline A14 & & 5 & $1^{*}$ \\
\hline A15 & 5 & 5 & $1 *$ \\
\hline A16 & 5 & 5 & $1 *$ \\
\hline A17 & 5 & 5 & $1 *$ \\
\hline
\end{tabular}

Mean expert Proportion $=0.89$

Note* Bold items indicated the desired CVI criteria.

Table 5. CVI for each question obtained from all the five experts under the 'Practice' section.

\begin{tabular}{|c|c|c|c|}
\hline \multicolumn{4}{|c|}{ Practice Section } \\
\hline Questions & No. in Agreement & Total number of Experts & CVI \\
\hline P1 & 4 & 5 & $0.8^{*}$ \\
\hline P2 & 4 & 5 & $0.8^{*}$ \\
\hline P3 & 4 & 5 & $0.8^{*}$ \\
\hline P4 & 5 & 5 & $1^{*}$ \\
\hline P5 & 5 & 5 & $1^{*}$ \\
\hline P6 & 5 & 5 & $1 *$ \\
\hline P7 & 4 & 5 & $0.8^{*}$ \\
\hline P8 & 4 & 5 & $0.8^{*}$ \\
\hline P9 & 5 & 5 & $1^{*}$ \\
\hline P10 & 4 & 5 & $0.8^{*}$ \\
\hline P11 & 4 & 5 & $0.8^{*}$ \\
\hline $\mathrm{P} 12$ & 5 & 5 & $1^{*}$ \\
\hline
\end{tabular}

Mean expert Proportion $=0.86$

Note* Bold items indicate the desired CVI criteria.

\section{DISCUSSION}

The questionnaire was developed in Hindi based upon literature review and expert's opinion having experience in $\mathrm{Cl}$, which consisted of 45 questions and were divided into knowledge, attitude, and practice sections and demographic section to contain the sociodemographic information of parents well as their children. After the questionnaire was developed, content validation was performed by five audiologists having more than five years of experience in $\mathrm{Cl}$. All the questions that had a relevant rating of " 4 " or " 5 " to obtain a criterion point higher than or equal to 0.8 , which was stated as the criteria point by Polit and Beck, (2004) for CVI, were included, and questions that have had $\mathrm{CVI}$ rating below 0.8 were discarded. After the validation procedure, the final version of the questionnaire consisted of 38 questions. Questions under knowledge were 14; the attitude section has
12 questions, and the practice section consisted of 12 questions.

The internal consistency of the questionnaire's content was assessed using a split-half test of reliability to calculate the Guttman split-half Coefficient. The analysis revealed that the questionnaire was highly reliable under all three sections; the reliability ranged from 0.94 to 1 . Mohamad et al. $(2015)^{8}$ stated that a correlation coefficient of 0.70 and above is enough to show test items be reliable.

\section{Parental Knowledge level on Hearing Impairment}

The present study noted that the overall level of parental knowledge on $\mathrm{HI}$ varies from fair $(31.6 \%)$ to poor $(7.9 \%)$ scores; however, the majority of the parents had good $(60.5 \%)$ knowledge. The results of the study done by ${ }^{9}$ on knowledge of mothers related to $\mathrm{HI}$ were similar to the present study findings, whereas ${ }^{10}$ reported high parental 
Table 6. Internal consistency reliable test results.

\begin{tabular}{ccc}
\hline & Guttman split-half Coefficient & \\
\hline Knowledge & 0.961 & 1.000 \\
Attitude & Practice & 0.940 \\
\hline
\end{tabular}

The analysis revealed that the questionnaire was highly reliable, and under all three sections, the reliability ranged from 0.94 to 1 .

Table 7: Parent's responses regarding knowledge about hearing impairment.

\begin{tabular}{|c|c|c|}
\hline Question No. & Yes & No \\
\hline $\mathrm{K} 1$ & 33 (86.8\%) & 5 (13.2\%) \\
\hline $\mathrm{K} 2$ & $32(84.2 \%)$ & $6(15.8 \%)$ \\
\hline K3 & 19 (50.0\%) & 19 (50.0\%) \\
\hline K4 & $23(60.5 \%)$ & 15 (39.5\%) \\
\hline K5 & $14(36.8 \%)$ & $24(63.2 \%)$ \\
\hline $\mathrm{K} 6$ & $8(21.1 \%)$ & 30 (78.9\%) \\
\hline $\mathrm{K} 7$ & 32 (84.2\%) & $6(15.8 \%)$ \\
\hline K8 & $21(55.3 \%)$ & $17(44.7 \%)$ \\
\hline K9 & $29(76.3 \%)$ & 9 (23.7\%) \\
\hline K10 & $10(26.3 \%)$ & $28(73.7 \%)$ \\
\hline $\mathrm{K} 11$ & 34 (89.5\%) & 4 (10.5\%) \\
\hline $\mathrm{K} 12$ & $31(81.6 \%)$ & 7 (18.4\%) \\
\hline K13 & $23(60.5 \%)$ & 15 (39.5\%) \\
\hline K14 & 33 (86.8\%) & 5 (13.2\%) \\
\hline
\end{tabular}

Table 8: Parent's responses regarding attitude towards hearing impairment.

\begin{tabular}{cccccc}
\hline Questions No & Always & Often & Sometimes & Seldom & Never \\
\hline A1 & $6(15.8 \%)$ & $1(2.6 \%)$ & $12(31.6 \%)$ & $1(2.6 \%)$ & $18(47.4 \%)$ \\
A2 & $1(2.6 \%)$ & $0(0 \%)$ & $5(13.2 \%)$ & $2(5.3 \%)$ & $30(78.9 \%)$ \\
A3 & $2(5.3 \%)$ & $0(0 \%)$ & $3(7.9 \%)$ & $2(5.3 \%)$ & $31(81.6 \%)$ \\
A4 & $20(52.6 \%)$ & $8(21.1 \%)$ & $6(15.8 \%)$ & $0(0 \%)$ & $4(10.5 \%)$ \\
A5 & $12(31.6 \%)$ & $4(10.5 \%)$ & $14(36.8 \%)$ & $2(5.3 \%)$ & $6(15.8 \%)$ \\
A6 & $3(7.9 \%)$ & $0(0 \%)$ & $4(10.5 \%)$ & $4(10.5 \%)$ & $6(15.8 \%)$ \\
A7 & $3(7.9 \%)$ & $4(10.5 \%)$ & $10(26.3 \%)$ & $0(0 \%)$ & $21(55.3 \%)$ \\
A8 & $6(15.8 \%)$ & $8(21.1 \%)$ & $10(26.3 \%)$ & $1(2.6 \%)$ & $13(34.2 \%)$ \\
A9 & $8(21.1 \%)$ & $2(5.3 \%)$ & $8(21.1 \%)$ & $3(7.9 \%)$ & $17(44.7 \%)$ \\
A10 & $1(2.6 \%)$ & $0(0 \%)$ & $4(10.5 \%)$ & $1(2.6 \%)$ & $32(84.2 \%)$ \\
A11 & $0(0 \%)$ & $1(2.6 \%)$ & $3(7.9 \%)$ & $2(5.3 \%)$ & $32(84.2 \%)$ \\
A12 & $3(7.9 \%)$ & $2(5.3 \%)$ & $2(5.3 \%)$ & $3(7.9 \%)$ & $28(73.7 \%)$ \\
\hline
\end{tabular}

Table 9: Parent's responses regarding practice towards hearing impairment.

\begin{tabular}{ccc}
\hline Question No & Yes & No \\
\hline P1 & $26(68.4 \%)$ & $12(31.6 \%)$ \\
P3 & $37(97.4 \%)$ & $1(2.6 \%)$ \\
P4 & $29(76.3 \%)$ & $9(23.7 \%)$ \\
P6 & $26(68.4 \%)$ & $12(31.6 \%)$ \\
P7 & $35(92.1 \%)$ & $3(7.9 \%)$ \\
P10 & $18(47.4 \%)$ & $20(52.6 \%)$ \\
\hline
\end{tabular}

knowledge levels in the Solomon Islands. In contrast11, reported average knowledge level in a survey conducted among mothers, and ${ }^{12}$ reported poor knowledge levels among parents towards $\mathrm{HI}$. In the current research, parents of children with good knowledge can be assumed to support better rehabilitation of $\mathrm{HI}$ children. However, a relatively lesser number of parents may not adequately help their children identify, assess, and rehabilitate hearing impairment due to a lack of knowledge. So, the parent's understanding of hearing loss is critical since they play an essential role in their children's health and well-being and in the successful implementation of early hearing detection and intervention programs ${ }^{13,14}$.

\section{Parental Attitude towards Hearing Impairment}

The present study results reveal that parental attitude towards their children's HI varies from (60.5\%) good to $(39.5 \%)$ fair. The overall parental attitude was shown to be high. Other studies obtained similar results ${ }^{12,15}$ as well. On the other hand, some studies reported poor and mixed 
Table 10: Association between the socio-demographic variables and parental knowledge, attitude, and practice towards hearing impairment.

\begin{tabular}{cc} 
Variables & Parental Knowledge \\
\hline $\begin{array}{c}\text { Level of education } \\
\text { Profession }\end{array}$ & Father \\
\hline Profession & $0.001^{*}$ \\
\hline & - \\
\hline Level of Education & Parental Attitude \\
\hline & $0.001^{*}$ \\
\hline
\end{tabular}

Note* Significant at $p \leq 0.05$ level

parental attitudes ${ }^{16,17}$. Parental attitudes play an essential role in rehabilitating disabled children. It may be helpful to include an attitude scale as a screening tool to assess parent's attitudes towards their hard-of-hearing children in addition to audiological, speech, and psychological evaluations. Because it could help us better understand parental attitudes and feelings towards their hard-ofhearing children and act as a guideline for counseling parents to help them make the necessary behavioral modifications for more effective rehabilitation ${ }^{17}$.

\section{Parental Practice towards Hearing Impairment}

In the present study, it was noted that the parental practice towards $\mathrm{HI}$ varies from good (63.2\%), (28.9\%) fair to $(7.9 \%)$ poor. However, most of the parents had good scores in the practice section. Thus, the finding of current research reveals overall good practice by parents of $\mathrm{HI}$ children, which means an appropriate program was given if children were diagnosed with $\mathrm{HI}$. This could be due to the National Programme for the Prevention \& Control of Deafness (NPPCD), which was started in 2007, and by 2017 it was introduced to include all the States and Union territories. One of the program's components is to increase the awareness among the general population about early identification and intervention ${ }^{18}$.

This variability in parents' knowledge, attitude, and practice towards $\mathrm{HI}$ could be because of the differences in the parents' geographical location, cultural beliefs and practices, family reactions on child's hearing loss, parents' education, age, and occupation. It is essential to improve parents' awareness regarding $\mathrm{HI}$ and services related to it as they are a critical part of their children's lives and play a crucial role in the rehabilitation program and the child's prognosis.

The current research also looked into the association between parentalknowledge, attitude, and practicetowards hearing impairment with socio-demographic variables like parental age, education level, and profession. The present study has found an association between fathers' knowledge on hearing impairment and the father's education level, mothers' knowledge on hearing impairment and mother's profession, father's attitude towards their children's hearing impairment, and fathers' profession and mothers' practice towards $\mathrm{HI}$ and the mothers' education level. Hence it can be understood that these above mention factors are essential in dealing with $\mathrm{HI}$ and may influence the rehabilitative outcome.

\section{CONCLUSION}

The developed questionnaire in hindi have good reliability and validity to assess parental knowledge, attitude, and practice about hearing impairment among parents of children with hearing impairment.

\section{LIMITATIONS}

The sample size of the present study was small, and participants were restricted to one state.

\section{CONFLICT OF INTEREST}

The authors declare that they have no conflicts of interest.

\section{ACKNOWLEDGEMENTS}

We wish to express our gratitude to Mr. Nirnay Kumar Keshree, Mr. Bhupendra Kurmi and Ms. Vanshika Vashishtha for their help in data collection.

\section{REFERENCES}

1. Vinila VJ, Ravichandran A, Santhi PS, Prakash SG, Narender K. Parental Needs of Transition of Children Using Cochlear Implants from Preschool to Inclusive School. Int j Special Education. 2013;28:45-55.

2. DesGeorges J. Family perceptions of early hearing, detection, and intervention systems: Listening to and learning from families. Mental Retardation and Developmental Disabilities Res Rev. 2003;9:89-93.

3. Alshehri KA, Alqulayti WM, Yaghmoor BE, Alem H. Public awareness of ear health and hearing loss in Jeddah, Saudi Arabia. South African J Communication Disorders. 2019;66:1-6.

4. Di Berardino F, Forti S, lacona E, Orlandi GP, Ambrosetti $U$, Cesarani A. Public awareness of ear and hearing management as measured using a specific questionnaire. Eur Arch of Oto-Rhino-Laryngol. 2013;270:449-53.

5. Mugenda OM, Mugenda AG. Research methods: Quantitative and qualitative approaches. Acts press; 1999.

6. Polit DF, Beck CT. The content validity index: are you sure you know what's being reported? Critique and recommendations. Research in nursing \& health. 2006;29:489-97.

7. Polit DF, Beck CT. Nursing research: Principles and methods. Lippincott Williams \& Wilkins; 2004.

8. Mohamad MM, Sulaiman NL, Sern LC, Salleh KM. Measuring the validity and reliability of research instruments. ProcediaSocial and Behavioral Sciences. 2015;204:164-71. 
9. Swanepoel D, Almec N. Maternal views on infant hearing loss and early intervention in a South African community. Int J Audiology. 2008;47:S44-8.

10. Kaspar A, Newton O, Kei J, Driscoll C, Swanepoel DW, Goulios H. Parental knowledge and attitudes to childhood hearing loss and hearing services in the Solomon Islands. Int J Pediatric Otorhinolaryngol. 2017;103:87-92.

11. Govender SM, Khan NB. Knowledge and cultural beliefs of mothers regarding the risk factors of infant hearing loss and awareness of audiology services. J Public Health in Africa. 2017;8(1).

12. Alsudays AM, Alharbi AA, Althunayyan FS, Alsudays AA, Alanazy SM, Al-Wutay $O$, et al. Parental knowledge and attitudes to childhood hearing loss and hearing services in Qassim, Saudi Arabia. BMC Pediatrics. 2020;20:1-6.

13. Swanepoel D, Almec N. Maternal views on infant hearing loss and early intervention in a South African community. Int J Audiol. 2008;47:S44-8.
14. HPCSA. The Health Professions Council of South Africa professional board for speech, language and hearing professions early hearing detection and intervention (ehdi) guidelines year 2018.

15. Wong YA, Mukari SZ, Harithasan D, Mazlan R. Knowledge and attitude on childhood hearing loss among mothers and mothers-to-be in urban and rural areas in Malaysia. Int $J$ Pediatric Otorhinolaryngol. 2019;124:79-84.

16. Frank-Briggs Al. Childhood Hearing Impairment: How do Parents Feel about it?. Nigerian Health J. 2012;12:102-5.

17. Kumar S, Rao G. Parental attitudes towards children with hearing impairment. Asia Pacific Disability Rehabili J. 2008;19:111-7.

18. NPPCD. National Programme for Prevention and Control of Deafness (NPPCD) Operational Guidelines for 12 th Five Year Plan. Ministry of Health \& Family Welfare Government of India. 2016. 